\title{
Interaction of smoking and atopy in producing specific IgE antibody against a hapten protein conjugate
}

\author{
K M VENABLES, M D TOPPING, W HOWE, C M LUCZYNSKA, R HAWKINS, \\ A J NEWMAN TAYLOR
}

\begin{abstract}
A survey was carried out of a population of workers exposed to tetrachlorophthalic anhydride, an acid anhydride epoxy resin curing agent known to cause asthma. Using a radioallergosorbent test with a tetrachlorophthalic anhydride human serum albumin conjugate, specific IgE antibody was detected in serum from 24 out of 300 factory floor workers exposed to tetrachlorophthalic anhydride. Of these $24,20(83.3 \%)$ were current smokers compared with $133(48.2 \%)$ of 276 without antibody $(p<0.01)$, and there was a weaker association with atopy, defined by skin tests with common allergens. Smoking and atopy interacted, the prevalence of antibody being $16.1 \%$ in atopic smokers, $11.7 \%$ in non-atopic smokers, $8.3 \%$ in atopic non-smokers, and nil in non-atopic non-smokers $(p<0.025)$. Smoking may predispose to, and interact with atopy in, the production of specific IgE antibody to this hapten protein conjugate.
\end{abstract}

\section{Introduction}

Acid anhydrides are reactive chemicals of low molecular weight, which are used as curing agents in epoxy resins and have applications in reinforced plastics, casting, encapsulation, paints, and adhesives. Acting as haptens, acid anhydrides stimulate the formation of specific IgE antibody, which is implicated in the mechanism of the asthma caused by acid anhydrides. ${ }^{1-3}$ In the United Kingdom patients with occupational asthma caused by acid anhydrides are now entitled to industrial disease benefit.

In 1978 Schlueter et al reported that the acid anhydride tetrachlorophthalic anhydride caused asthma, ${ }^{4}$ and in 1983 we described a group of seven patients with asthma induced by tetrachlorophthalic anhydride and also showed specific IgE antibody in their serum in a radioallergosorbent test using a tetrachlorophthalic anhydride human serum albumin conjugate. ${ }^{3}$ Only one of these seven patients was atopic, defined by skin rerctivity to common environmental antigens, but all seven were smokers.

A survey of the population at the factory that had employed the patients in our first study ${ }^{3}$ provided an opportunity to

Department of Occupational Medicine, Brompton Hospital, London SW3 6HP

$\mathrm{K} M$ VENABLES, MSC, MRCP, clinical lecturer

R HAWKINS, SRN, research assistant

A J NEWMAN TAYLOR, MSC, MRCP, department director and consultant physician

Occupational Medicine and Hygiene Laboratories, Health and Safety Executive, London

M D TOPPING, PHD, senior scientific officer

C M LUCZYNSKA, MSC, scientific officer

Employment Medical Advisory Service, Health and Safety Executive, Darlington, County Durham

W HOWE, AFOM, MRCGP, employment medical adviser

Correspondence to: Dr K M Venables. study factors (particularly smoking) potentially predisposing people to asthma induced by tetrachlorophthalic anhydride. Paradoxically, patients are not ideal subjects for studies of risk factors in occupational asthma. They are often selected for medical referral because they have severe or complicated disease, and their symptoms may cause them to alter their working practices and other habits, like smoking, or may colour their recollection of events preceding the onset of asthma. The ability to detect specific IgE immunoglobulin against occupational agents causing asthma means that surveys can use a standard, objective case definition and also permits the study of healthy people with specific IgE who are without the symptoms that may lead a patient with asthma to modify his way of life.

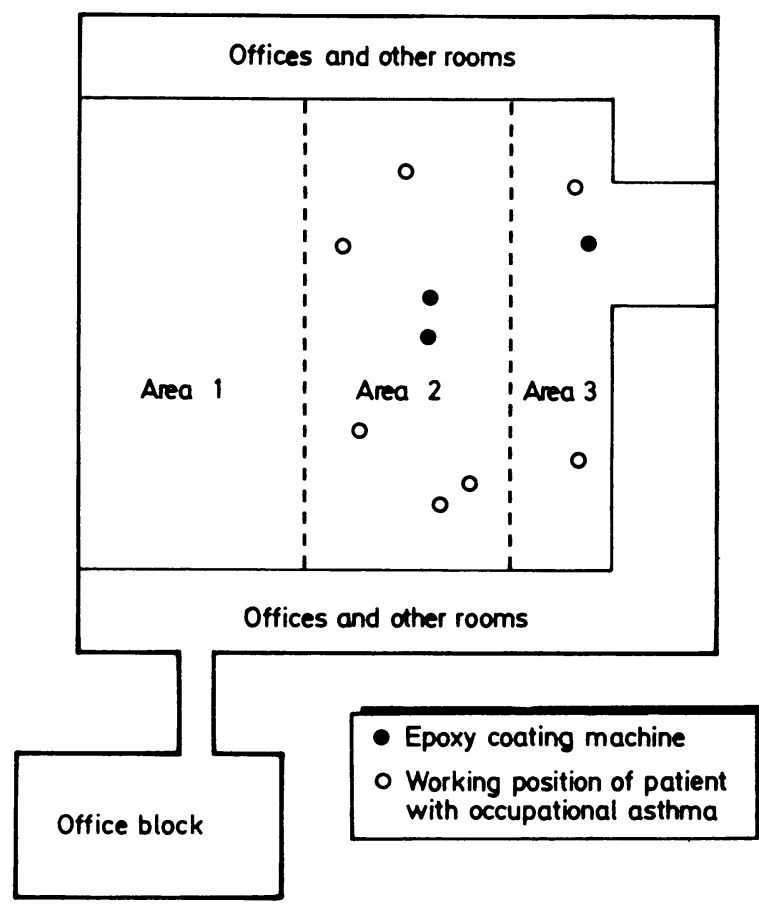

FIG 1-Factory plan. Areas 1,2 , and 3 are functional areas in the open plan factory. Patients' working positions are those at the time they developed tetrachlorophthalic anhydride induced asthma; the patients left the firm in 1980 .

\section{Subjects and methods}

THE FACTORY

The factory was used for the manufacture of electronic components, most of which were encapsulated in epoxy plastic containing tetrachlorophthalic anhydride. The encapsulation process was performed using uncured, premixed epoxy resin powder in coating machines whose positions are shown in figure 1 . The process allowed powder to escape into the environment, where it could be inhaled. The factory was open plan but could be divided functionally into area 1 , where the early stages of manufacture were performed, and areas 2 and 3 , where coating and other finishing operations occurred and where the original patients had worked. Offices and other rooms were situated around the periphery of the factory, and the building was linked by a 
corridor to an office block. Tetrachlorophthalic anhydride was used in coating from 1979 until the survey in December 1981, and the patients' symptoms followed its introduction, starting between December 1979 and September 1980. During 1980 the bright blue resin powder was seen in all parts of the factory, particularly the coating areas 2 and 3 , but was not seen in the office block. The original patients were made redundant in 1980, and during the year it took to obtain agreement for this survey the firm made further redundancies. In addition, measures were taken to control exposure to epoxy resin dust.

\section{METHODS}

We performed a cross sectional survey of all workers employed at the firm on 1 December 1981. The original seven women with occupational asthma had left by that date and were not included.

Questionnaire-The subjects completed a questionnaire about their symptoms, smoking habit, and occupational history. Chest symptoms potentially attributable to sensitisation by tetrachlorophthalic anhydride were defined as "chest tightness or difficulty in breathing" or "wheezing or whistling in the chest" lasting for at least 15 minutes, improving either at weekends or on holiday, and starting after first exposure to tetrachlorophthalic anhydride-that is, after joining the firm during 1979-81 when tetrachlorophthalic anhydride was in use. Symptoms of "blocking, itching, or running nose" potentially attributable to sensitisation by tetrachlorophthalic anhydride were defined similarly. Chronic bronchitis was defined as a productive cough on most days for at least three months each year, and the subjects were classified as current or former smokers or non-smokers.

fob mapping-The subjects indicated their working positions on a large plan of the factory, on which a grid had been drawn. In this study current work area was used as an index of exposure to tetrachlorophthalic anhydride, and the subjects were divided into three exposure groups-coating area workers (areas 2 and 3 (fig 1)), other factory workers (area 1 plus factory rooms and offices and workers without a fixed working position), and office block workers.

Serum antibody-Specific IgE antibody against tetrachlorophthalic anhydride human serum albumin conjugate was detected using the radioallergosorbent test as previously described, ${ }^{3}$ and results were expressed as per cent binding. The per cent binding to human serum albumin was subtracted from that to tetrachlorophthalic anhydride human serum albumin conjugate to correct for any nonspecific binding to human serum albumin, so some values became negative. Before log transformation all values were made positive by adding one throughout. Sera from the seven patients with asthma induced by tetrachlorophthalic anhydride were run in parallel with the survey sera for comparison.

Skin tests-Solutions of $1 \%$ tetrachlorophthalic anhydride human serum albumin conjugate and $1 \%$ human serum albumin were prepared as previously described. ${ }^{3} \mathrm{~B} 2$ grass pollen, cat fur, and house dust mite solutions (Bencard) and diluent and histamine control solutions were also used. Skin prick tests were performed on the flexor surface of the forearm and read at 10 minutes. A reaction to tetrachlorophthalic anhydride human serum albumin conjugate was defined as any weal greater than any weal elicited by human serum albumin, and atopy was defined as at least one weal to a common antigen of at least $2 \mathrm{~mm}$ diameter after subtraction of the diameter of any weal elicited by the diluent control. Results were excluded if no reaction was elicited by any agent, including the histamine control, or if reactions were elicited by all agents, including the diluent and human serum albumin controls.

Clinical history-Two chest physicians each interviewed half the subjects and took a brief history, directed at asthma and its relation to work, without knowledge of the symptoms and smoking and occupational histories already recorded in the questionnaire or of the results of the skin tests. People with a history of work related asthma or with a skin reaction to tetrachlorophthalic anhydride human serum albumin conjugate were interviewed again at greater length by one physician.

Absentees-Twelve people were absent from work during the survey and were seen shortly afterwards by one of us (WH), following the same protocol.

Statistical tests-A statistical package on a Prime 750 computer was used for most tests. Differences were tested by analysis of variance, Student's $t$ test, the Mann-Whitney U test, the $\chi^{2}$ test, and Fisher's exact test. The presence of an interaction was tested using the method of generalised linear models. ${ }^{5} \mathrm{~A}$ p value of 0.05 or less was regarded as significant.

\section{Results}

Of 419 employees, $400(95.5 \%)$ completed the questionnaire, $396(94.5 \%)$ mapped their jobs, $386(92.1 \%)$ were interviewed, $377(90.0 \%)(358(85.4 \%)$ after exclusions) underwent skin tests, and $356(85.0 \%)$ gave a blood sample. Complete information was available on $329(82.3 \%)$ of the 400 respondents. A relatively high proportion of the non-respondents and those giving incomplete information were office workers with little or no exposure to tetrachlorophthalic anhydride.

Figure 2 shows the distribution of per cent binding to tetrachlorophthalic anhydride human serum albumin conjugate with the values in the seven patients' sera included for comparison. The binding in sera from 54 office block workers was lower than in sera from factory floor workers and was used as the normal range for this factory. Binding greater than $2.5 \mathrm{SD}$ above the geometric mean for

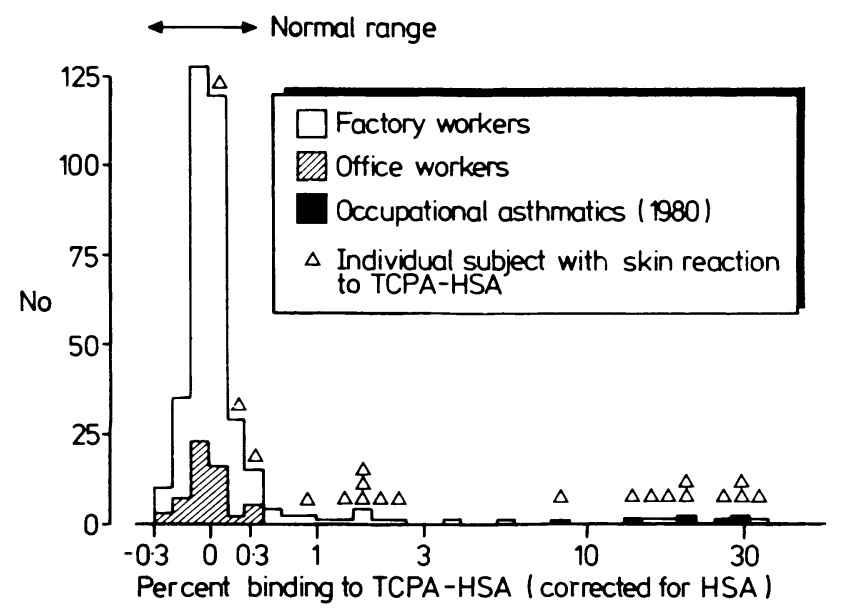

FIG 2-Distribution of per cent binding to tetrachlorophthalic anhydride human serum albumin conjugate (TCPA-HSA). Normal range $(-0 \cdot 294 \%$ $+0.379 \%$ ) calculated from the transformed office workers' binding, which was normally distributed and fell within $2.5 \mathrm{SD}$ of their geometric mean. Untransformed binding is presented for clarity, but the histogram was constructed using transformed binding. Binding in patients with tetrachlorophthalic anhydride induced asthma in 1980 is included for comparison.

office workers, equivalent to $0.38 \%$ or greater, was taken to indicate specific IgE antibody against tetrachlorophthalic anhydride human serum albumin conjugate. There were 24 factory workers with specific IgE in the range $0.38 \%$ to $31 \cdot 16 \%$. This overlapped the range in the blood samples taken in 1980 from the original patients but was lower $(\mathrm{p}<0.001)$. Specific IgE and skin reactivity to tetrachlorophthalic anhydride human serum albumin conjugate were associated $(p<0.001)$, but, unlike the patients, who all had skin reactions, only 11 of the 24 survey subjects with specific $\operatorname{IgE}$ had skin reactions; 10 did not react, two results were excluded, and one declined the tests. There were two people with skin reactions but without specific IgE.

Table I shows characteristics of the population by work area. None of the office workers had a skin reaction to tetrachlorophthalic anhydride human serum albumin conjugate, which supported the decision to use their serum binding values as a normal range. The prevalence of both specific IgE and skin reactivity to tetrachlorophthalic anhydride human serum albumin conjugate was higher in the coating areas than in the other factory areas, reflecting exposure to tetrachlorophthalic anhydride. The sex distribution was significantly different $(\mathrm{p}<0.001)$ because most coating area workers were women. There was a trend in nasal symptoms to follow the level of exposure to tetrachlorophthalic anhydride but not in chest symptoms.

Table II shows these characteristics for the two groups of factory workers combined and classified by binding to tetrachlorophthalic anhydride human serum albumin conjugate. The 24 with specific IgE, on average, had worked longer with the firm and were older than the 276 with normal binding. More $(20(83.3 \%))$ of those with antibody were current smokers than those without (133 $(48.2 \%)$ ). Atopy was also more common in those with specific IgE but not significantly so. The sex distribution was similar, and the differences in prevalence of symptoms were explicable by chance.

Table III summarises a significant interaction that was noted between smoking, atopy, and specific $\operatorname{IgE}(\mathrm{p}<0.025)$. There was a trend in preva- 
TABLE I-Characteristics-of population by work area

\begin{tabular}{|c|c|c|c|c|}
\hline & \multicolumn{2}{|c|}{ Factory } & \multirow{2}{*}{$\begin{array}{c}\text { Office } \\
\text { block } \\
(n=66)\end{array}$} & \multirow{2}{*}{$\begin{array}{l}\mathrm{p} \\
\text { value }\end{array}$} \\
\hline & $\begin{array}{l}\text { Coating areas } \\
(n=187)\end{array}$ & $\begin{array}{l}\text { Other areas } \\
(\mathrm{n}=143)\end{array}$ & & \\
\hline \multirow{9}{*}{ 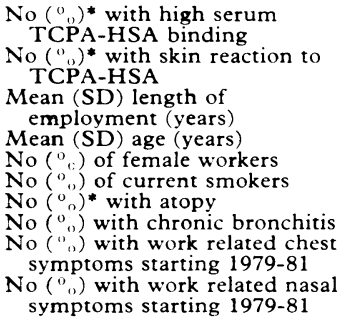 } & $17(10.0)$ & $7(5 \cdot 4)$ & 0 & NA \\
\hline & $9(5 \cdot 3)$ & $4(3 \cdot 1)$ & 0 & ND \\
\hline & $5 \cdot 6(4 \cdot 3)$ & $6.6(5.5)$ & $6 \cdot 6(5 \cdot 6)$ & NS \\
\hline & $35.9(10.9)$ & $38 \cdot 5(11 \cdot 2)$ & $37 \cdot 2(11 \cdot 0)$ & NS \\
\hline & $163(87 \cdot 2)$ & $53(37 \cdot 1)$ & $36(54.5)$ & $<001$ \\
\hline & $\begin{array}{l}97(51 \cdot 9) \\
41(24 \cdot 1)\end{array}$ & $\begin{array}{l}70(49.0) \\
28(21.9)\end{array}$ & $\begin{array}{l}26(39 \cdot 4) \\
11(19 \cdot 0)\end{array}$ & $\begin{array}{l}\text { NS } \\
\text { NS }\end{array}$ \\
\hline & $18(9 \cdot 6)$ & $16(11 \cdot 2)$ & $8(12 \cdot 1)$ & NS \\
\hline & $7(3 \cdot 7)$ & $2(1 \cdot 4)$ & $2(3 \cdot 0)$ & ND \\
\hline & $19(10 \cdot 2)$ & $6(4 \cdot 2)$ & $1(1.5)$ & $<0.025$ \\
\hline
\end{tabular}

Denominator less than group total.

$\mathrm{NA}=$ statistical test inappropriate.

$\mathrm{ND}=$ statistical test not done (small numbers)

NS = not significan

TABLE II-Characteristics of factory workers by level of serum tetrachlorophthalic anhydride human serum albumin conjugate (TCPA-HSA) binding

\begin{tabular}{|c|c|c|c|}
\hline & $\begin{array}{l}\text { High } \\
\text { binding } \\
(\mathrm{n}=\mathbf{2 4})\end{array}$ & $\begin{array}{l}\text { Normal } \\
\text { binding } \\
(\mathrm{n}=276)\end{array}$ & p value \\
\hline 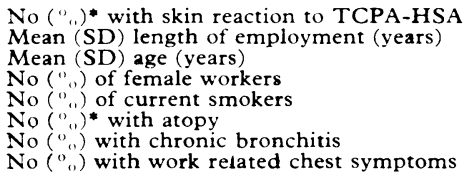 & $\begin{array}{l}11(52 \cdot 4) \\
8 \cdot 5(9 \cdot 2) \\
41 \cdot 6(9 \cdot 2) \\
15(62 \cdot 5) \\
20(83 \cdot 3) \\
8(38 \cdot 1) \\
2(8 \cdot 3)\end{array}$ & $\begin{array}{l}2(0 \cdot 8) \\
5 \cdot 9(4 \cdot 8) \\
36 \cdot 9(11 \cdot 1) \\
180(65 \cdot 2) \\
133(48 \cdot 2) \\
59(23 \cdot 1) \\
30(10 \cdot 9)\end{array}$ & $\begin{array}{l}<0.001 \\
<0.05 \\
<0.05 \\
\text { NS } \\
<0.01 \\
\text { NS } \\
\text { NS }\end{array}$ \\
\hline $\begin{array}{l}\text { starting } 1979-81 \\
\text { No ("). with work related nasal symptoms }\end{array}$ & $1(4 \cdot 2)$ & $7(2 \cdot 5)$ & NS \\
\hline starting $1979-81$ & 0 & $25(9 \cdot 1)$ & NS \\
\hline
\end{tabular}

*Denominator less than group total.

$\mathrm{NS}=$ not significant $(\mathrm{p}, 0.05)$

TABLE III-Prevalence of specific IgE antibody to tetrachlorophthalic anhydride human serum albumin conjugate in factory workers grouped by smoking habit and atopic state

\begin{tabular}{|c|c|c|c|c|c|c|}
\hline & \multicolumn{2}{|c|}{ Current smokers } & \multicolumn{2}{|c|}{$\begin{array}{l}\text { Former smokers } \\
\text { and non-smokers }\end{array}$} & \multicolumn{2}{|c|}{ Total } \\
\hline & $\mathrm{No}^{*}\left({ }^{0}{ }_{0}\right)$ & Total & No* $\left({ }^{0}{ }_{1}\right)$ & Total & $\mathrm{No}^{*}\left({ }^{0}{ }_{0}\right)$ & Total \\
\hline $\begin{array}{l}\text { Atopic } \\
\text { Not atopic }\end{array}$ & $\begin{array}{r}5(16 \cdot 1) \\
13(11 \cdot 7)\end{array}$ & $\begin{array}{r}31 \\
111\end{array}$ & $\begin{array}{l}3(8 \cdot 3) \\
0\end{array}$ & $\begin{array}{l}36 \\
98\end{array}$ & $\begin{array}{r}8(11 \cdot 9) \\
13(6 \cdot 2)\end{array}$ & $\begin{array}{r}67 \\
209\end{array}$ \\
\hline Total & $18(12 \cdot 7)$ & 142 & $3(2 \cdot 2)$ & 134 & $21(7 \cdot 6)$ & 276 \\
\hline
\end{tabular}

*Number with specific IgE.

Test for interaction, $p<0.025$

lence of specific IgE from atopic smokers (16.1\%) to non-atopic nonsmokers $(0)$. Length of employment showed a non-significant reverse trend, with atopic smokers having the shortest mean duration. Neither age nor sex showed a trend. Smoking and atopy were not associated per se. In the normal range of binding mean binding did not differ significantly by atopic state or smoking habit, or by combinations of the two. Three subjects with specific IgE were excluded from this analysis because their atopic state was not known; two were current and one a former smoker. The two subjects with a skin reaction to tetrachlorophthalic anhydride human serum albumin conjugate but without serum antibody were non-atopic current smokers.

In the interviews five workers gave histories consistent with work related asthma but in none could tetrachlorophthalic anhydride be implicated convincingly. Two had low concentrations of specific IgE $\left(0.42^{\circ} \%\right.$ and $\left.0.47^{\circ}\right)$ but they, and a third subject, identified other agents as provoking their symptoms-a solder, an ink, and an unidentified black powder in use four years previously. All three had moved away from these materials and improved despite remaining exposed to tetrachlorophthalic anhydride. The two others with positive histories had also remained exposed to tetrachlorophthalic anhydride, and their asthma had not deteriorated. No skin reactions to tetrachlorophthalic anhydride human serum albumin conjugate were elicited in this group. For follow up they were referred to the local employment medical advisory service.

\section{Discussion}

We found no further cases of occupational asthma caused by tetrachlorophthalic anhydride in this workforce, perhaps because of the firm's redundancy programme. Nasal symptoms were associated with work area but not with specific IgE against tetrachlorophthalic anhydride human serum albumin conjugate and may have been caused by non-specific irritation by dust or fumes. The 24 people with specific IgE were therefore a group with immunological reactivity to tetrachlorophthalic anhydride but without clinical hypersensitivity and therefore without reason to modify their work or smoking.

The striking finding of the study was the association between smoking and specific $\operatorname{IgE}$ and the interaction between smoking and atopy. In workers exposed to the chemical the prevalence of antibody was over five times greater in smokers than in non-smokers, and, although the association with atopy was weaker, both smoking and atopy were related to specific IgE production. With both factors the antibody prevalence was $16.1 \%$, with smoking alone $11.7 \%$, and with atopy alone $8.3 \%$; people without either factor, over one third of the exposed population, had not developed antibody. These results were not explained by differences in, for example, length of employment and suggest that smoking and, to a lesser extent, atopy predisposed to the development of specific IgE.

A similar association between smoking and specific IgE has been noted in a Swedish study of green coffee bean and ispaghula workers, ${ }^{6}$ although the effect of atopy on the association was not examined. This consistency suggests that the association may be causal. The mechanism is unknown, but as these protein antigens would be denatured by heat, exposure is unlikely to be enhanced in some way by smoking contaminated cigarettes. A possible explanation is that smoking increases antigen access to immunocompetent cells. Smokers' lungs are more permeable to inhaled agents, ${ }^{7}$ probably because of the acute inflammation produced by cigarette smoke. ${ }^{8}$ The longstanding "mucosal theory" of atopy proposes that increased mucosal permeability to antigenic material may explain atopy. ${ }^{9}$ It would also explain both the association with smoking and the interaction with atopy that we observed. Increased mucosal permeability also may be a factor in the higher mean concentration of total IgE observed in smokers in the general population. ${ }^{10}$

The 24 workers found to have specific IgE did not have asthma induced by tetrachlorophthalic anhydride and differed from our original patients in having a lower mean antibody concentration and a lower prevalence of skin reactivity to tetrachlorophthalic anhydride human serum albumin conjugate. These differences may reflect current exposure to tetrachlorophthalic anhydride, which was lower during the survey than when the patients were diagnosed; they may refect clinical state, with asymptomatic antibody production and clinical asthma representing the ends of a spectrum of disease. The prognostic significance of asymptomatic antibody production is unknown without further investigation.

Extrapolating to the prevention of occupational asthma, we would not recommend, on the basis of these results, that atopic persons be excluded from employment exposing them to tetrachlorophthalic anhydride. The association with atopy was weak and was not seen in the patients, only one of whom was atopic, but the association with smoking was stronger and all the patients were smokers, suggesting that, with control of exposure to tetrachlorophthalic anhydride, discouragement of smoking should minimise the risk of specific IgE production and of asthma. Smoking may even be a preventable risk factor for occupational asthma in general.

We thank Drs A Harrison, M Dally, S Burge, and I Coutts for 
helping during the survey and Mr A Nunn for his advice on aspects of the statistical analysis.

\section{References}

1 Maccia CA, Bernstein IL, Emmett EA, Brooks SM. In vitro demonstration of specific IgE in phthalic anhydride hypersensitivity. Am Rev Respir Dis 1976, specific 18:701-4.

2 Zeiss CR, Patterson R, Pruzansky JJ, Miller MM, Rosenberg M, Levitz D Trimellitic anhydride-induced airway syndromes: clinical and immunologic

3 Howe W, Venables KM, Topping MD, et al. Tetrachlorophthalic anhydride asthma: evidence for specific IgE antibody. $\mathfrak{f}$ Allergy Clin Immunol 1983;71:
4 Schlueter DP, Banaszak EF, Fink JN, Barboriak J. Occupational asthma due to tetrachlorophthalic anhydride. F Occup Med 1978;20:183-8.

5 Nelder JA, Wedderburn RWM. Generalized linear models. Fournal of the Royal Statistical Society Part A 1972;135:370-8

Zetterström O, Osterman K, Machado L, Johansson SGO Another smokin hazard: raised serum I $\dot{g} E$ ' concentration and increased risk of occupational llergy. Br Med f 1981;283:1215-7.

7 Jones JG, Minty BD, Royston D, Royston JP. Carboxyhaemoglobin and pul monary epithelial permeability in man. Thorax 1983;38:129-33.

C. Airway permeability to horse(anjer by cigarette radish peroxidase in guinea pigs: the rep.
smoke. Am Rev Respir Dis $1981 ; 123: 320-6$.

9 Leskowitz S, Salvaggio JE, Schwarz HJ. An hypothesis for the development of atopic allergy in man. Clin Allergy 1972;2:237-46.

10 Burrows $\mathrm{B}$, Halonen M, Barbee RA, Lebowitz MD. The relationship of serum immunoglobulin E to cigarette smoking. Am Rev Respir Dis 1981;124:523-5.

(Accepted 8 October 1984)

\section{SHORT REPORTS}

\section{Support hose and varicose veins}

Despite the successful clinical use of support hose for many years the exact amount of compression required to give maximum benefit to patients with varicose veins is still disputed. ${ }^{12}$ Physiological studies have shown that the tension and pressure of support hose should be close to the capillary pressure, ${ }^{3-5}$ but as the capillary pressure varies with posture and the distance from the heart this is technically difficult to achieve. We investigated the acceptability of a stocking that is claimed by the manufacturer (Sigvaris, Ganzoni, St Gallen, Switzerland) to provide graduated support with a pressure of roughly $40 \mathrm{~mm} \mathrm{Hg}$ at the level of the ankle.

\section{Patients, methods, and results}

Patients were selected sequentially from a surgical waiting list, starting with those added most recently. They were randomised into two groups and given stockings that provided either $30-40 \mathrm{~mm} \mathrm{Hg}$ or $40-50 \mathrm{~mm} \mathrm{Hg}$ pressure. For each patient a history was taken and an examination made for the presence of pain, eczema, and ulceration and the extent of varicosities. The patients were fitted with support hose below the knee and asked to wear the stockings for six weeks. They were then reviewed blind, particular attention being paid to tolerance of the stockings and whether symptoms were better, worse, or unchanged.

Altogether 163 patients were asked to take part in the trial. Twenty five did not reply because they had moved from the area, four had had operation elsewhere, and 30 declined to participate. Thus 104 patients entered the trial, of whom 53 were randomised to wear stockings providing $30-40 \mathrm{~mm} \mathrm{H}$ pressure and 51 stockings providing $40-50 \mathrm{~mm} \mathrm{Hg}$ pressure. The groups were evenly matched for age, symptomatology, and extent of varicose veins. On review nine patients given the $30-40 \mathrm{~mm} \mathrm{Hg}$ stockings and 13 given the $40-50 \mathrm{~mm} \mathrm{Hg}$ stockings asked for their names to be removed from the waiting list because their symptoms had improved. In all, 42 patients given the $30-40 \mathrm{~mm} \mathrm{Hg}$ stockings and 40 given the $40-50 \mathrm{~mm} \mathrm{Hg}$ stockings claimed symptomatic improvement (table). Their overall feeling of benefi was not due to improvement in any one particular symptom. An attempt to analyse the effect of the two types of stocking on particular symptoms was unsuccessful because the subgroups were too small.

Results in patients asked to take part in trial

\begin{tabular}{|c|c|c|c|c|}
\hline & $\begin{array}{c}\text { No of } \\
\text { patients }\end{array}$ & $\begin{array}{l}\text { Remained on } \\
\text { waiting list }\end{array}$ & $\begin{array}{l}\text { Stockings } \\
\text { improved symptoms }\end{array}$ & $\begin{array}{l}\text { Came off } \\
\text { waiting list }\end{array}$ \\
\hline $\begin{array}{l}\text { Non-participants } \\
\text { Participants: }\end{array}$ & 59 & 30 & & 29 \\
\hline $\begin{array}{l}30-40 \mathrm{~mm} \mathrm{Hg} \\
40-50 \mathrm{~mm} \mathrm{Hg}\end{array}$ & $\begin{array}{l}53 \\
51\end{array}$ & $\begin{array}{l}44 \\
38\end{array}$ & $\begin{array}{l}42 \\
40\end{array}$ & $\begin{array}{r}9 \\
13\end{array}$ \\
\hline Total & 163 & 112 & 82 & 51 \\
\hline
\end{tabular}

\section{Comment}

We reduced our waiting list by 51 patients simply by conducting this trial. Of the 104 patients who took part in the trial, $8 \mathrm{C}$ claimed that the stockings were comfortable. In the remaining group of patients the main cause of discomfort was not simply that they were too tight. In answer to the proponents of low pressure stockings, most of our patients found the higher pressure stockings tolerable and roughly one quarter found them sufficiently acceptable that they decided not to undergo surgery. We could have increased the acceptability of the stockings by varying their weight and length (for example, above knee length or tights), but for consistency within the trial we did not offer different styles to the patients.

We accept that the study was biased towards surgery because patients were taken from the waiting list and therefore may have considered stockings to be second best; but we believe that this bias was probably offset by our giving those patients who were not keen on surgery an alternative method of treatment. Despite these reser vations we believe that the trial showed that most patients with simple varicose veins tolerate pressures of about $40 \mathrm{~mm} \mathrm{Hg}$ and that suggestions that lower pressures are more acceptable are too cautious. ${ }^{1}$

We thank Lesley Davies for typing the manuscript, Mr L James, who acted as fitter, and Sigvaris Company for providing the stockings.

Fentem PH. Claims about compression treatment for venous disease. $\mathrm{Br}$ Med $\mathcal{f}$

Che 1982;285:439.

Chant ADB. The effects of posture, exercise and bandage pressure on the clearance of $24 \mathrm{Na}$ from the subcutaneous tissues of the foot. Br $\mathcal{F}$ Surg 1972;59:552-5. Spiro M, Roberts VC, Richards JB. Effect of externally applied pressure on

5 Jones NAG, Webb PJ, Rees RI, Kakkar VV. A physiological study of elastic compression stockings in venous disorders of the leg. Brf S Surg 1980;67:569-72. (Accepted 23 October 1984)

Department of Vascular Surgery, Royal South Hants Hospital, Southampton SO9 4PE

A D B CHANT, FRCs, consultant surgeon P MAGNUSSEN, FRCS, surgical registrar C KERSHAW, FRCS, surgical registrar

Correspondence to: Mr A D B Chant.

\section{Mixing short and intermediate acting insulins in the syringe: effect on postprandial blood glucose concentrations in type $I$ diabetics}

Many diabetics take combinations of short and intermediate acting insulin, and they often mix them in the syringe before administration. We have recently shown that mixing short acting and isophane insulins in the syringe does not affect the absorption kinetics of the short acting insulin, whereas its activity is delayed when it is combined with lente insulin. ${ }^{2}$ This study compared the effects of mixtures of short acting with lente and short acting with isophane insulins on postprandial blood glucose and plasma free insulin concentrations in type I diabetics.

\section{Patients, methods, and results}

We studied 13 type I diabetics aged 19-64 who did not secrete endogenous insulin. They were treated with twice daily mixtures of short and inter- 